\title{
Thyroid Dysfunction in Children with Idiopathic Nephrotic Syndrome Attending a Paediatric Hospital in Qazvin, Iran
}

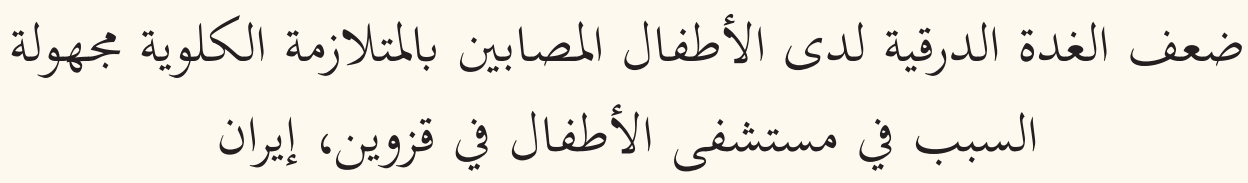

فاطمة صفاري، سامية أهدي، رضا داليراني، نسرين اسفنديار، زهرة يزدي، بانفشة عراد

ABSTRACT: Objectives: Nephrotic syndrome is a glomerular disease characterised by a loss of albumin and high-molecular-weight proteins such as thyroxine-binding globulin and thyroid hormones, potentially resulting in subclinical or even overt hypothyroidism. This study aimed to compare thyroid hormone levels between nephrotic children and healthy controls as well as between nephrotic children in the active phase of the disease and those in remission. Methods: This case-control study was conducted between March 2016 and 2018 at a paediatric hospital in Qazvin, Iran. A total of 73 nephrotic children comprised the case group-including 49 with active disease and 24 in remission-while the control group included 74 healthy children. Thyroid function was assessed according to levels of thyroid-stimulating hormone (TSH), free triiodothyronine (T3), free thyroxine (T4), total T4, total T3 and anti-thyroid peroxidase. Results: All of the controls had normal total T4 levels. Elevated TSH levels were more frequent in nephrotic children compared to controls $(34.2 \%$ versus $10.8 \% ; P=0.001$ ). A significantly lower number of patients with active disease were euthyroid compared to those in remission $(51 \%$ versus $95.8 \% ; P=0.001)$. Moreover, $7(9.5 \%)$ of patients in the active and no patient in remission phase had abnormal total T4 levels $(P<0.001)$, while $14.3 \%$ and $0 \%$ had highly elevated TSH levels $(P=0.002)$. Conclusion: Due to the prevalence of subclinical and even overt hypothyroidism, thyroid screening tests may be required for nephrotic children. However, further research is needed to confirm these findings.

Keywords: Nephrotic Syndrome; Children; Albuminuria; Proteinuria; Hypothyroidism; Iran.

الملخص: الهذف: متلازمة التنفرزالكلوية هي مرض يصيب الجلوميريولات يتميز بفقدان الألبومين والبروتينات عالية الوزن الجزئن الجزيئي

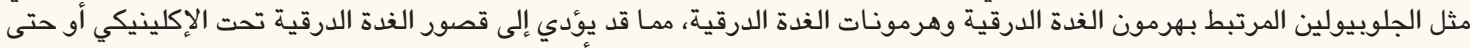

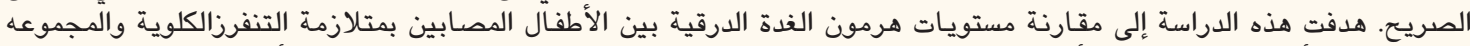

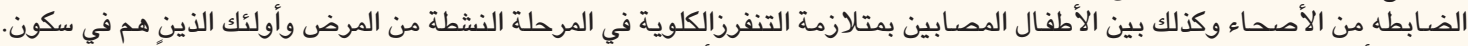

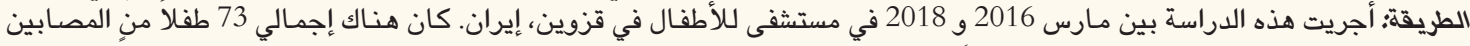

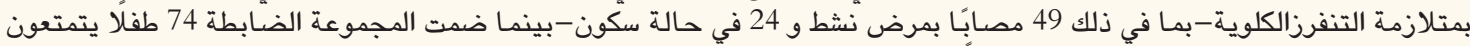

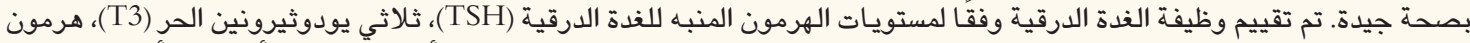

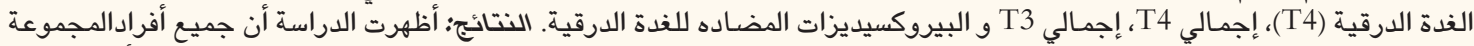

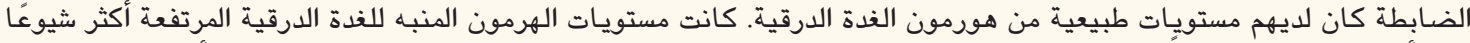

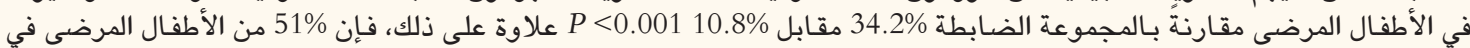

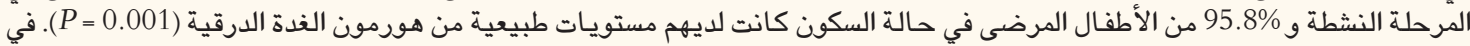

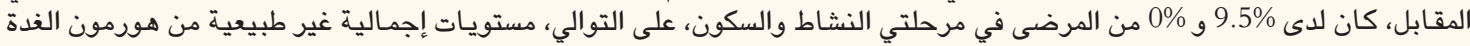

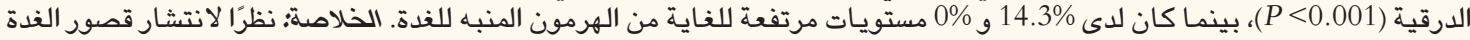

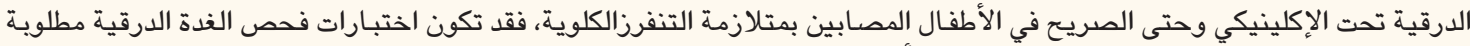

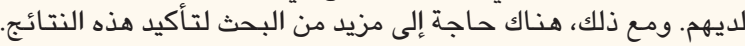

الكلمات المفتاحية: متلازمة التنفر الكلوية؛ الأطفال؛ بيلة الألبومين؛ بيلة البروتينات؛ قصور الغدة الدرقية؛ إيران.

\section{AdVAnCES in KNOWLEDge}

This study found that the most common thyroid disorder among children with active nephrotic syndrome was subclinical hypothyroidism, a feature closely related to hypercholesterolaemia and hypoalbuminaemia .

Moreover, nephrotic syndrome mostly affected levels of thyroid-stimulating hormone and total thyroxine levels, with no impact on free and total triiodothyronine levels. 


\section{Application to Patient Care}

This study highlighted the importance of measuring levels of thyroid hormones in children with nephrotic syndrome in order to determine the prevalence of subclinical or overt hypothyroidism in this population.

$\mathrm{I}$ DIOPATHIC NEPHROTIC SYNDROME (INS) IS A common paediatric glomerular disease characterised by symptoms of severe proteinuria-as defined by a urinary protein-to-creatinine ratio of $>2$ in the first morning sample or a rate of $>40 \mathrm{mg} /$ $\mathrm{m}^{2}$ /hour over 24 hours-hypoalbuminaemia $(<2.5 \mathrm{~g} /$ $\mathrm{dL})$, oedema and serum cholesterol $(>250 \mathrm{mg} / \mathrm{dL}){ }^{1,2}$ Moreover, recent studies have shown that nephrotic children may develop thyroid hormone dysfunction as the result of the urinary excretion of thyroidbinding globulin, transthyretin and thyroid hormones; however, the exact prevalence of thyroid disorders in this population has not yet been defined as thyroid tests are not conducted on a routine basis. ${ }^{3}$

Thyroid function disorders can lead to changes in fluid homeostasis and electrolytes; for instance, hypothyroidism decreases glomerular sodium filtration, thereby affecting urine osmolality. ${ }^{4}$ Approximately $4-10 \%$ of the general population is affected by subclinical hypothyroidism. ${ }^{5}$ In particular, nephrotic children with low thyroid reserves may develop subclinical hypothyroidism which, without thyroxine (T4) replacement therapy, will likely progress to overt hypothyroidism. ${ }^{6}$ Hence, the need for T4 replacement therapy in patients with hypothyroidism is increased in the presence of nephrotic syndrome.? Thyroid hormonal therapy in children with subclinical hypothyroidism and short stature has been shown to improve growth velocity, especially in prepubertal groups, although other researchers have reported contradictory findings. ${ }^{8,9}$ In addition, treatment for hypothyroidism has been observed to improve renal function. ${ }^{10}$

In light of the aforementioned evidence, the aim of this study was to compare levels of thyroid hormones between nephrotic children and healthy controls, as well as between nephrotic children in the active phase of the disease and those in remission.

\section{Methods}

This case-control study was carried out between March 2016 and March 2018 at a children's hospital in Qazvin, Iran. The case group consisted of children aged 1-12 years with nephrotic syndrome who were being examined in the nephrology department or outpatient clinic of the hospital during the study period. In addition, a control group was recruited consisting of healthy children without any metabolic or infectious diseases who were admitted to the hospital for elective surgery during the same timeframe. The necessary sample size for the case group was determined to be 70 nephrotic children based on a two-sided confidence level (1-alpha) equal to 0.95 and at $80 \%$ power. ${ }^{11}$ Sampling continued in succession until this target was met. As such, the final cohort consisted of 73 nephrotic children in the case group, including 49 with active disease and 24 in remission, and 74 healthy children in the control group.

Nephrotic children in the case group were deemed to have INS if they met the following parameters: (1) a urinary protein-to-creatinine ratio of $>2$ in the first morning sample or a rate of $>40 \mathrm{mg} / \mathrm{m}^{2} /$ hour over 24 hours; (2) a serum albumin level of $<2.5 \mathrm{~g} / \mathrm{dL}$; (3) oedema; and (4) a serum cholesterol level of $>250 \mathrm{mg} /$ dL. Children with congenital nephrotic syndrome, nephrotic syndrome secondary to infection, metabolic or other disorders and those with acute or chronic renal failure were excluded. Blood samples were taken from all the children to measure their serum levels of albumin, cholesterol, free T4, free triiodothyronine (T3), total T4, total T3, thyroid-stimulating hormone (TSH) and anti-thyroid peroxidase (TPO). In the control group, these tests were performed on initial blood samples requested for elective surgery. In the case group, these tests were performed for all nephrotic patients regardless of whether they were in the active phase of the disease or in remission. The personnel who analysed the samples were not aware of whether the samples originated from patients or controls.

Laboratory tests for thyroid hormones were performed using an enzyme-linked immunosorbent assay (PISHSAZ TEB, ELIZA KIT, model 50104475, $481 \mathrm{CPC}$, Iran). In addition, an endpoint assay (PARS AZMUN CO, 3311 ISIC, Iran) was used to determine levels of albumin and cholesterol oxidase. Urine samples were collected and the proportion of protein to random urinary creatinine was measured, with ratios of $>2$ considered to indicate nephrotic-range proteinuria. Children with elevated serum TSH levels (5-10 mIU/L) and normal free T4 levels (i.e. within the reference range) were considered to have subclinical hypothyroidism. ${ }^{12}$ Hypothyroidism was considered as high TSH levels (>10 mIU/L) with normal thyroid hormone levels that require levothyroxine replacement therapy, or high TSH levels with decreased total T3 and T4 and/or free T3 and T4 [Table 1]. ${ }^{13}$ 
Table 1: Criteria used to define thyroid function categories in the current study

\begin{tabular}{lccccc} 
Category & & \multicolumn{3}{c}{ Hormone levels } & \\
& Total T3* & Total T4 & & Free T3 & \\
Euthyroidism & Normal & Normal & Normal & Normal & Normal \\
Hypothyroidism & Low & Low & Low & Low & High \\
Subclinical hypothyroidism & Normal & Normal & Normal & Normal & High
\end{tabular}

T3 = triiodothyronine; T4 = thyroxine; TSH = thyroid-stimulating hormone. *Normal ranges for children aged $1-6$ years and 7-12 years are 0.92-2.48 ng/mL and $0.93-2.30 \mathrm{ng} / \mathrm{mL}$, respectively. ${ }^{+}$Normal ranges for children aged $1-6$ years and $7-12$ years are $5.95-14.7 \mu \mathrm{g} / \mathrm{dL}$ and $5.99-13.80 \mu \mathrm{g} / \mathrm{dL}$, respectively. ${ }^{7}$ Normal ranges for children aged 1-6 years and $7-12$ years are $2.41-5.50 \mathrm{pg} / \mathrm{mL}$ and $2.53-5.22 \mathrm{pg} / \mathrm{mL}$, respectively. ${ }^{\mathbb{S}}$ Normal ranges for children aged $1-6$ years and $7-12$ years are $0.96-1.77 \mathrm{ng} / \mathrm{dL}$ and $0.97-1.67 \mathrm{ng} / \mathrm{dL}$, respectively. Normal ranges for children aged $1-6$ years and $7-12$ years are 0.70-5.97 mIU/L and 0.60-4.84 mIU/L, respectively. "High TSH levels (>10 mIU/L) and normal levels of thyroid hormones was also considered hypothyroidism.

Initially, none of the nephrotic patients underwent kidney biopsies due to the absence of gross haematuria, hypertension, renal insufficiency or hypocomplementemia and were instead treated with daily prednisolone therapy. ${ }^{14}$ However, four did not respond to treatment following eight weeks of prednisolone therapy; these cases were diagnosed with steroidresistant nephrotic syndrome and subsequently underwent diagnostic kidney biopsies. Two patients had focal and segmental glomerulonephritis, one had lupus nephritis and one had mesangioprolifrative glomerulonephritis.

Data were analysed using the Statistical Package for the Social Sciences (SPSS), Version 18.0 (IBM Corp., Armonk, New York, USA). Continuous variables were presented using means and standard deviations while categorical variables were expressed in frequencies and percentages. Either a Chi-squared test or Fisher's exact test (for variables with $<5$ data points) was used to compare the prevalence of thyroid function abnormalities between two groups (i.e. between patients and controls or between patients with active disease and those in remission). In addition, a Kolmogorov-Smirnov test was used to determine the distribution of numerical data. Comparisons between three groups (i.e. nephrotic children categorised into three groups according to TSH level) were carried out using a Kruskal-Wallis test, while comparisons between two groups (i.e. between patients with active disease and those in remission) were carried out using a Mann-Whitney U test. A $P$ value of $<0.050$ was considered statistically significant.

This study was approved by the Ethics Committee of the Research Department at the Qazvin University of Medical Sciences (IR.QUMS.REC.1395.269). In addition, written informed consent was provided on behalf of the children by their parents or legal guardians.

\section{Results}

The mean age of the nephrotic children was $5.2 \pm 3$ years and 41 (56.2\%) were male. The mean age of control group was $5.4 \pm 3.4$ and 32 (43.2\%) were male. Overall, there was a significantly higher proportion of nephrotic children with low total T4 levels compared to the control group $(9.5 \%$ versus $0 \%$; $P$ $<0.001)$. Moreover, a significantly higher number of nephrotic children had elevated TSH levels compared to the control group (34.2\% versus $10.8 \%$; $P=0.001$ ). No significant differences were noted between the nephrotic children and healthy controls for any other thyroid hormone abnormalities [Table 2].

Thyroid test results were subsequently compared between nephrotic patients with active disease and those in remission. A total of 7 (9.5\%) and no patients in the active and remission phases, respectively,

Table 2: Frequency of thyroid hormone abnormalities among nephrotic children and healthy controls $(\mathrm{N}=147)$

\begin{tabular}{|lccc}
\hline Abnormality & \multicolumn{2}{c}{ n (\%) } & $\begin{array}{c}P \\
\text { value }^{*}\end{array}$ \\
& $\begin{array}{c}\text { Nephrotic } \\
\text { children } \\
(\mathbf{n}=73)\end{array}$ & $\begin{array}{c}\text { Control } \\
\text { group } \\
(\mathbf{n}=74)\end{array}$ & \\
\hline Decreased total T3 & $18(24.7)$ & $17(23)$ & 0.848 \\
\hline Decreased total T4 & $7(9.5)$ & $0(0)$ & $<0.001$ \\
\hline Decreased free T3 & $11(15.1)$ & $6(8.1)$ & 0.208 \\
\hline Decreased free T4' & $9(12.3)$ & $5(6.8)$ & 0.276 \\
\hline Increased TSH & $25(34.2)$ & $8(10.8)$ & 0.001 \\
\hline $\begin{array}{l}\text { Increased anti- } \\
\text { TPO }\end{array}$ & $2(2.7)$ & $3(4.1)$ & $>0.999$ \\
\hline
\end{tabular}

T3 = triiodothyronine; $T 4=$ thyroxine; $T S H=$ thyroid - stimulating hormone; TPO = thyroid peroxidase. "Calculated using a Chi-squared test or Fisher's exact test for variables with $<5$ data points. ${ }^{\dagger}$ Normal ranges for children aged 1-6years and 7-12 years are $0.92-2.48 \mathrm{ng} / \mathrm{mL}$ and $0.93-2.30 \mathrm{ng} / \mathrm{mL}$, respectively. ${ }^{\ddagger}$ Normal ranges for children aged 1-6 years and 7-12 years are $5.95-14.7 \mu \mathrm{g} / \mathrm{dL}$ and $5.99-13.80 \mu \mathrm{g} / \mathrm{dL}$, respectively. ${ }^{\mathbb{S}}$ Normal ranges for children aged 1-6 years and 7-12 years are $2.41-5.50 \mathrm{pg} / \mathrm{mL}$ and 2.53-5.22 pg/mL, respectively. Normal ranges for children aged 1-6 years and $7-12$ years are $0.96-1.77 \mathrm{ng} / \mathrm{dL}$ and $0.97-1.67 \mathrm{ng} / \mathrm{dL}$, respectively. "Normal ranges for children aged 1-6 years and 7-12 years are 0.70-5.97 mIU/L and 0.60-4.84 mIU/L, respectively. "Normal range for children aged $1-12$ years is $<2 \mathrm{IU} / \mathrm{mL}$. 
Table 3: Mean levels of thyroid hormones according to disease phase among nephrotic children $(\mathrm{N}=73)$

\begin{tabular}{|c|c|c|c|}
\hline \multirow[t]{2}{*}{ Hormone } & \multicolumn{2}{|c|}{ Mean level \pm SD } & \multirow{2}{*}{$\begin{array}{c}P \\
\text { value }^{*}\end{array}$} \\
\hline & $\begin{array}{c}\text { Active } \\
\text { phase } \\
(\mathrm{n}=49)\end{array}$ & $\begin{array}{l}\text { Remission } \\
\text { phase } \\
(\mathbf{n}=24)\end{array}$ & \\
\hline Total $\mathrm{T} 3$ in $\mathrm{ng} / \mathrm{mL}^{\dagger}$ & $1.82 \pm 0.53$ & $2.41 \pm 0.53$ & 0.009 \\
\hline Total T4 in $\mu \mathrm{g} / \mathrm{dL}^{\ddagger}$ & $4.83 \pm 1.70$ & $7.93 \pm 1.80$ & $<0.001$ \\
\hline Free $\mathrm{T} 3$ in $\mathrm{pg} / \mathrm{mL}^{\S}$ & $3.91 \pm 1.10$ & $3.70 \pm 0.85$ & 0.557 \\
\hline Free T4 in ng/dL & $9.60 \pm 2.54$ & $12.30 \pm 2.80$ & 0.002 \\
\hline $\mathrm{TSH}$ in $\mathrm{mIU} / \mathrm{L}^{\prime \prime}$ & $7.12 \pm 7.90$ & $2.70 \pm 1.71$ & $<0.001$ \\
\hline $\begin{array}{l}\text { Anti-TPO in } \\
\mathrm{IU} / \mathrm{mL}^{* *}\end{array}$ & $0.73 \pm 2.30$ & $0.33 \pm 0.41$ & 0.737 \\
\hline
\end{tabular}

T3 = triiodothyronine; T4 = thyroxine; TSH = thyroid-stimulating hormone TPO = thyroid peroxidase. *Calculated using a Mann-Whitney U test. ${ }^{+}$Normal ranges for children aged $1-6$ years and $7-12$ years are $0.92-2.48$ $n g / m L$ and $0.93-2.30 \mathrm{ng} / \mathrm{mL}$, respectively. ${ }^{*}$ Normal ranges for children aged $1-6$ years and 7-12 years are 5.95-14.7 $\mu \mathrm{g} / \mathrm{dL}$ and $5.99-13.80 \mu \mathrm{g} / \mathrm{dL}$, respectively. "Normal ranges for children aged 1-6 years and 7-12 years are $2.41-5.50 \mathrm{pg} / \mathrm{mL}$ and $2.53-5.22 \mathrm{pg} / \mathrm{mL}$, respectively. Normal ranges for children aged 1-6 years and 7-12 years are 0.96-1.77 $\mathrm{ng} / \mathrm{dL}$ and $0.97-1.67 \mathrm{ng} / \mathrm{dL}$, respectively. "Normal ranges for children aged 1-6 years and $7-12$ years are $0.70-5.97 \mathrm{mIU} / \mathrm{L}$ and $0.60-4.84 \mathrm{mIU} / \mathrm{L}$, respectively. *NNNormal range for children aged $1-12$ years is $<2 \mathrm{IU} / \mathrm{mL}$.

had abnormal total T4 levels $(P<0.001)$. Moreover, 24 (49\%) patients with active disease had slightly elevated TSH levels ( $>5 \mathrm{mIU} / \mathrm{L})$ in comparison to one $(4.2 \%)$ patient in remission $(P<0.001)$, while highly elevated TSH levels $(>10 \mathrm{mIU} / \mathrm{L})$ were observed in seven $(14.3 \%)$ patients with active disease and none of the patients in remission $(P=0.002)$. There were no significant differences in other thyroid hormone abnormalities between the two groups. Significantly higher mean TSH levels $(P<0.001)$ and significantly lower mean total T4 $(P<0.001)$ and free T4 levels $(P$ $=0.002)$ were observed among patients with active disease in comparison to those in remission [Table 3].

A significantly lower number of patients with active disease had euthyroidism compared to those in remission (51\% versus 95.8\%; $P=0.001$ ).
Table 4: Thyroid function according to disease phase among nephrotic children $(\mathrm{N}=73)$

\begin{tabular}{|c|c|c|c|}
\hline \multirow[t]{2}{*}{ Category } & \multicolumn{2}{|c|}{ n (\%) } & \multirow{2}{*}{$\begin{array}{c}P \\
\text { value }^{*}\end{array}$} \\
\hline & $\begin{array}{l}\text { Active } \\
\text { phase } \\
(\mathrm{n}=49)\end{array}$ & $\begin{array}{c}\text { Remission } \\
\text { phase } \\
(\mathbf{n}=24)\end{array}$ & \\
\hline Euthyroidism $^{\dagger}$ & $25(51)$ & $23(95.8)$ & 0.001 \\
\hline Hypothyroidism $^{\ddagger}$ & $7(14.3)$ & $0(0)$ & 0.001 \\
\hline $\begin{array}{l}\text { Subclinical } \\
\text { hypothyroidism }^{\S}\end{array}$ & $17(34.7)$ & $1(4.2)$ & 0.001 \\
\hline
\end{tabular}

T3 = triiodothyronine; T4 = thyroxine. "Calculated using a Chi-squared test or Fisher's exact test for variables with $<5$ data points. ${ }^{\dagger}$ Defined as normal levels of all thyroid hormones. ${ }^{*}$ Defined as high levels of thyroidstimulating hormone (TSH; 5-10 mIU/L) and low levels of total T3 and total T4 and/or low levels offree T3 and free T4, as well as highly elevated TSH levels (>10 mIU/L) with normal levels of thyroid hormones. "Defined as high levels of TSH $(5-10 \mathrm{mIU} / \mathrm{L})$ and normal levels of total T3, total T4, free T3 and free T4.

However, significantly higher rates of subclinical hypothyroidism $(34.7 \%$ versus $4.2 \% ; P=0.001)$ and hypothyroidism (14.3\% versus $0 \% ; P=0.001)$ were noted in patients with active disease [Table 4]. Predictive factors for highly elevated TSH levels $(>10$ $\mathrm{mIU} / \mathrm{L})$ included hypoalbuminaemia $(P=0.004)$ and hypercholesterolaemia $(P<0.001)$ [Table 5 ]. Although the prevalence of highly elevated TSH levels $(>10$ $\mathrm{mIU} / \mathrm{L})$ was higher in female children, this difference was not statistically significant $(P=0.117)$.

\section{Discussion}

This study aimed to compare thyroid hormone levels between nephrotic children and healthy controls as well as between nephrotic children in the active phase of the disease and those in remission. While the case and control groups did not differ significantly in terms of levels of total T3, free T3, free T4 and antiTPO, a significantly higher proportion of nephrotic patients demonstrated abnormal total T4 and TSH levels compared to the healthy controls. Fonseca et

Table 5: Mean levels of thyroid-stimulating hormone, albumin, triglycerides, cholesterol and urine protein/creatinine level according to age group among nephrotic children $(\mathrm{N}=73)$

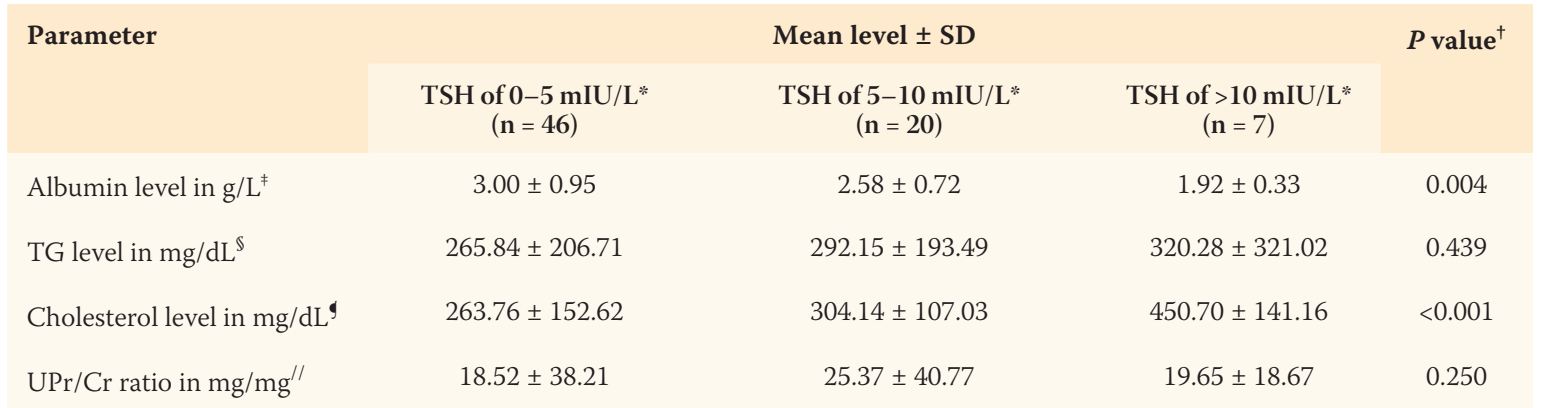

$S D=$ standard deviation; $T S H=$ thyroid-stimulating hormone; $I U=$ international unit; $T G=$ triglycerides; UPr = urinary protein; $C r=$ creatinine. ${ }^{*}$ Normal ranges for children aged $1-6$ years and $7-12$ years are $0.70-5.97 \mathrm{mIU} / \mathrm{L}$ and $0.60-4.84 \mathrm{mIU} / \mathrm{L}$, respectively. ${ }^{\dagger}$ Calculated using a KruskalWallis test. "Fypoalbuminaemia was defined as $<2.5 \mathrm{~g} / \mathrm{L}$. "Hypertriglyceridaemia was defined as $<75 \mathrm{mg} / \mathrm{dL}$ and $<90 \mathrm{mg} / \mathrm{dL}$ for children aged $0-9$ and 10-19years, respectively. 'Hypercholesterolaemia was defined as $>250 \mathrm{mg} / \mathrm{dL}$. "Nephrosis was defined as $>2 \mathrm{mg} / \mathrm{mg}$. 
al. reported significantly lower free $\mathrm{T} 4$ and free $\mathrm{T} 3$ levels in nephrotic patients for whom high urinary T4 levels were detected. ${ }^{15}$ While the current study did note significantly lower free T4 levels among nephrotic children in the active phase of the disease, no significant differences were observed with regards to free T3 levels between nephrotic patients with active disease and those in remission.

Ito et al. found that children with nephrotic syndrome had lower serum T3 and T4 levels in the active phase of the disease compared to the remission phase; moreover, mean free $\mathrm{T} 4$ and free T3 concentrations were lower in untreated nephrotic patients. ${ }^{13}$ The researchers also observed that most nephrotic children had normal TSH values, with a negative correlation between serum albumin and TSH levels. ${ }^{13}$ In contrast, the prevalence of subclinical hypothyroidism (as defined by high levels of TSH alone) was higher among nephrotic children in the present study, although there was a significant association noted between hypoalbuminaemia and highly elevated serum TSH levels.

Hajizadeh et al. reported that $34.7 \%$ of children with active nephrotic syndrome had high TSH levels; this rate was close to that observed in the present study (46.9\%). ${ }^{11}$ Furthermore, the mean TSH level among untreated nephrotic children was $11.65 \pm 6.71 \mathrm{mIU} / \mathrm{L}$ (range: $4.31-34.40 \mathrm{mIU} / \mathrm{L}){ }^{11}$ This is comparable to the mean TSH level of nephrotic patients with active disease in the current study (7.12 \pm 7.90 $\mathrm{mIU} / \mathrm{L}$ ). Finally, the researchers noted a relationship between TSH levels and the severity of proteinuria, hypoalbuminaemia and hypertriglyceridaemia. ${ }^{11}$ In the present study, while both hypoalbuminaemia and hypercholesterolaemia were significantly associated with serum TSH levels, there was no association with proteinuria or hypertriglyceridaemia.

Much like the present study, Ebadi et al. reported that children with nephrotic syndrome had low T4 and high TSH levels; however, the researchers also observed low T3 levels, a finding not observed in the current study. ${ }^{16}$ Afroz et al. described significantly higher TSH levels in children with nephrotic syndrome (mean: $9.11 \pm 6.36 \mathrm{mIU} / \mathrm{L}$ ), with a negative correlation with serum albumin levels, but normal total T4 levels. ${ }^{17}$ Guo et al. indicated that nephrotic children had lower serum albumin levels and higher TSH levels; overall, elevated TSH levels were detected in 44.51\% of nephrotic children, a lower percentage compared to that noted in the current study (34.2\%). ${ }^{18}$ Bona et al. observed significant associations between highly elevated TSH levels ( $>10 \mathrm{mIU} / \mathrm{L})$ and initial TSH levels of $>7.5 \mathrm{mIU} / \mathrm{L}$ as well as the female gender, but not with age. ${ }^{19}$ While female children in the present study did more frequently demonstrate highly elevated TSH levels (>10 mIU/L) compared to males, this difference was not statistically significant.

In children diagnosed with nephrotic syndrome, the loss of binding proteins through urine (such as thyroxine-binding proteins, albumin and thyroid hormones) can result in a decrease in serum levels of thyroid hormones and an increase in TSH levels as a compensatory mechanism. ${ }^{18}$ Previous research has also confirmed differences in thyroid profiles in nephrotic patients..$^{20}$ The urinary loss of total T3, total T4 and thyroid-binding globulin occurs during the proteinuric phase of nephrotic syndrome and subsequently reverts during the remission phase. ${ }^{13}$ In addition, high levels of thyroid hormones bind to plasma proteins that cross the glomerular barrier and are briefly reabsorbed by proximal tubule. The free T4 with two iodine atoms in phenolic ring are mainly reabsorbed by the tubules, while free $\mathrm{T} 3$ with one iodine atom in phenolic ring is mostly secreted. ${ }^{15,21}$

A portion of nephrotic patients can manifest with euthyroid sick syndrome, a condition characterised by low total T3 and total T4 levels and increased reverse T3 levels, but normal-to-low TSH levels. ${ }^{13}$ This syndrome results from a decrease in the activity of type $15^{\prime}$-deiodinase, the hepatic enzyme that deiodinates T4 to the biologically active T3. ${ }^{22}$ In some patients, the expression of TSH in the pituitary gland is inhibited by the prolonged use of glucocorticoids, oxidative activation and psychological stress, thus resulting in normal or even low TSH levels. ${ }^{23}$ In the current study, significantly lower free T4 and total T4 levels were observed in the active phase of nephrotic syndrome in comparison with the remission phase; however, there was no difference in free T3 and total T3 levels. In an assessment of thyroid hormones among outpatients, Legakis et al. revealed that T3 and TSH levels were practically independent, while T4 and TSH levels had a significant negative correlation; moreover, there was a positive correlation between T3 and T4 levels that became more pronounced with age. ${ }^{24}$ These correlations could explain the normal T3 levels noted in the present study compared to other reports. ${ }^{13,15,16}$

Subclinical hypothyroidism is less common in children and adolescents than in adults. ${ }^{25}$ Indeed, the progression of this condition to overt hypothyroidism has been reported in $0-12.5 \%$ of cases. ${ }^{26}$ Predictors for this include serum TSH level above $7.5 \mathrm{mIU} / \mathrm{L}$ and female gender, however age was not significant predictor. $^{19}$ However, it can prove difficult to distinguish between euthyroid patients and those with mild or overt thyroid disease. ${ }^{5}$ Thyroid disorders impact fluid haemostasis, electrolyte levels, glomerular 
filtration rate and urine osmolality, thereby leading to fluid retention. ${ }^{4,27}$ Moreover, patients with subclinical hypothyroidism (i.e. highly elevated TSH levels of $>10 \mathrm{mIU} / \mathrm{L}$ ) have an increased risk of cardiovascular morbidity and mortality compared to patients with lower serum TSH levels due to high serum cholesterol levels and other cardiac risk factors. ${ }^{28}$ As such, thyroid hormone assessment is strongly recommended for nephrotic patients with elevated serum cholesterol levels.

The present study was subject to certain limitations including the small sample size and short follow-up period which did not permit adequate detection of hypothyroid abatement in cases of subclinical hypothyroidism. The authors therefore recommend further studies be conducted incorporating a longer follow-up period in order to determine whether there is a need for treatment in nephrotic children with subclinical hypothyroidism.

\section{Conclusion}

Few studies have sought to assess the prevalence of subclinical and overt hypothyroidism in the presence of INS. This study conducted comparative thyroid hormone assessments for both nephrotic children and healthy controls, as well as for nephrotic children in the active phase of the disease and those in remission. While it remains unclear whether subclinical hypothyroidism influences the natural history and prognosis of nephrotic syndrome, the findings of this study underline the importance of conducting thyroid function tests in nephrotic children with prolonged and severe urinary protein loss.

\section{ACKNOWLEDGEMENTS}

The preliminary version of this research was submitted as part of a PhD thesis in the field of paediatrics to the School of Medicine, Qazvin University of Medical Sciences, in 2016. The authors wish to thank the parents and their children for their participation in the study as well as the staff of the Center for Clinical Research at Qazvin Children's Hospital for their help in preparing this manuscript for publication.

\section{CONFLICT OF INTEREST}

The authors declare no conflicts of interest.

\section{FUNDING}

This research was funded with the aid of a grant (28/20/13577) from the Research Department of the Qazvin University of Medical Sciences.

\section{References}

1. Uwaezuoke SN. Steroid-sensitive nephrotic syndrome in children: Triggers of relapse and evolving hypotheses on pathogenesis. Ital J Pediatr 2015; 41:19. https://doi.org/10.1186/ s13052-015-0123-9.

2. Lombel RM, Gipson DS, Hodson EM. Treatment of steroidsensitive nephrotic syndrome: New guidelines from KDIGO. Pediatr Nephrol 2013; 28:415-26. https://doi.org/10.1007/s004 67-012-2310-x.

3. Iglesias P, Díez JJ. Thyroid dysfunction and kidney disease. Eur J Endocrinol 2009; 160:503-15. https://doi.org/10.1530/EJE-080837.

4. Gilles R, den Heijer M, Ross AH, Sweep FC, Hermus AR, Wetzels JF. Thyroid function in patients with proteinuria. Neth J Med 2008; 66:483-5. https://doi.org/10.1530/EJE-08-0837.

5. McDermott MT, Ridgway EC. Subclinical hypothyroidism is mild thyroid failure and should be treated. J Clin Endocrinol Metab 2001; 86:4585-90. https://doi.org/10.1210/jcem.86.1 0.7959 .

6. Di Mario F, Pofi R, Gigante A, Rivoli L, Rosato E, Isidori AM, et al. Hypothyroidism and nephrotic syndrome: Why, when and how to treat. Curr Vasc Pharmacol 2017; 15:398-403. https://doi.or g/10.2174/1570161115999170207114706.

7. Junglee NA, Scanlon MF, Rees DA. Increasing thyroxine requirements in primary hypothyroidism: Don't forget the urinalysis! J Postgrad Med 2006; 52:201-3.

8. Cetinkaya E, Aslan AT, Vidinlisan S, Ocal G. Height improvement by L-thyroxine treatment in subclinical hypothyroidism. Pediatr Int 2003; 45:534-7. https://doi.org/10.1046/j.1442200X.2003.01786.x.

9. Rapa A, Monzani A, Moia S, Vivenza D, Bellone S, Petri A, et al. Subclinical hypothyroidism in children and adolescents: A wide range of clinical, biochemical, and genetic factors involved. J Clin Endocrinol Metab 2009; 94:2414-20. https:// doi.org/10.1210/jc.2009-0375

10. den Hollander JG, Wulkan RW, Mantel MJ, Berghout A. Correlation between severity of thyroid dysfunction and renal function. Clin Endocrinol (Oxf) 2005; 62:423-7. https://doi. org/10.1111/j.1365-2265.2005.02236.x.

11. Hajizadeh N, Marashi SM, Nabavizadeh B, Elhami E, Mohammadi T, Nobandegani NM, et al. Examine of thyroid function in pediatric nephrotic syndrome: Tehran-Iran. Int J Pediatr 2015; 3:59-65. https://doi.org/10.22038/IJP.2015.4051.

12. Crisafulli G, Aversa T, Zirilli G, Pajno GB, Corica D, De Luca F, et al. Subclinical hypothyroidism in children: When a replacement hormonal treatment might be advisable. Front Endocrinol (Lausanne) 2019; 10:109. https://doi.org/10.3389/ fendo.2019.00109.

13. Ito S, Kano K, Ando T, Ichimura T. Thyroid function in children with nephrotic syndrome. Pediatr Nephrol 1994; 8:412-15. https://doi.org/10.1007/BF00856516.

14. Kliegman RM, St. Geme J. Nelson Textbook of Pediatrics. 21st ed. Amsterdam, Netherlands: Elsevier, 2019. P. 2757.

15. Fonseca V, Thomas M, Katrak A, Sweny P, Moorhead JF. Can urinary thyroid hormone loss cause hypothyroidism? Lancet 1991; 338:475-6. https://doi.org/10.1016/0140-6736 (91)90546-2.

16. Ebadi A, Shirali S, Daneghian S, Saki S. Evaluating the thyroid function in pediatric nephrotic syndrome: A study conducted in Ahvaz, Iran. Int J Pharm Res Allied Sci 2016; 5:82-5.

17. Afroz S, Khan AH, Roy DK. Thyroid function in children with nephrotic syndrome. Mymensingh Med J 2011; 20:407-11.

18. Guo QY, Zhu QJ, Liu YF, Zhang HJ, Ding Y, Zhai WS, et al. Steroids combined with levothyroxine to treat children with idiopathic nephrotic syndrome: A retrospective singlecenter study. Pediatr Nephrol 2014; 29:1033-8. https://doi. org/10.1007/s00467-013-2727-x. 
19. Bona G, Prodam F, Monzani A. Subclinical hypothyroidism in children: Natural history and when to treat. J Clin Res Pediatr Endocrinol 2013; 5:23-8. https://doi.org/10.4274/jcrpe.851.

20. Dagan A, Cleper R, Krause I, Blumenthal D, Davidovits M. Hypothyroidism in children with steroid-resistant nephrotic syndrome. Nephrol Dial Transplant 2012; 27:2171-5. https:// doi.org/10.1093/ndt/gfr665.

21. Faber J, Siersbaek-Nielsen K, Kirkegaard C. Renal handling of thyroxine, 3,5,3'- and 3,3',5'-triiodothyronine, 3,3'- and 3',5'diiodothyronine in man. Acta Endocrinol (Copenh) 1987; 115:144-8. https://doi.org/10.1530/acta.0.1150144.

22. Liu H, Yan W, Xu G. Thyroid hormone replacement for nephrotic syndrome patients with euthyroid sick syndrome: A meta-analysis. Ren Fail 2014; 36:1360-5. https://doi.org/10.310 9/0886022X.2014.949559.

23. Warner MH, Beckett GJ. Mechanisms behind the non-thyroidal illness syndrome: An update. J Endocrinol 2010; 205:1-13. https://doi.org/10.1677/JOE-09-0412.

24. Legakis I, Manousaki M, Detsi S, Nikita D. Thyroid function and prevalence of anti-thyroperoxidase (TPO) and antithyroglobulin ( $\mathrm{Tg}$ ) antibodies in outpatients hospital setting in an area with sufficient iodine intake: Influences of age and sex. Acta Med Iran 2013; 51:25-34.
25. Wasniewska M, Salerno M, Cassio A, Corrias A, Aversa T, Zirilli G, et al. Prospective evaluation of the natural course of idiopathic subclinical hypothyroidism in childhood and adolescence. Eur J Endocrinol 2009; 160:417-21. https://doi. org/10.1530/EJE-08-0625

26. Radetti G, Gottardi E, Bona G, Corrias A, Salardi S, Loche S, et al. The natural history of euthyroid Hashimoto's thyroiditis in children. J Pediatr 2006; 149:827-32. https://doi.org/10.1530/ EJE-08-0625oi.org/10.1530/EJE-08-0625.

27. Chonchol M, Lippi G, Salvagno G, Zoppini G, Muggeo M, Targher G. Prevalence of subclinical hypothyroidism in patients with chronic kidney disease. Clin J Am Soc Nephrol 2008; 3:1296-300. https://doi.org/10.2215/CJN.00800208.

28. Rodondi N, den Elzen WP, Bauer DC, Cappola AR, Razvi S, Walsh JP, et al. Subclinical hypothyroidism and the risk of coronary heart disease and mortality. JAMA 2010; 304:1365-74. https://doi.org/10.1001/jama.2010.1361. 